\title{
A CONSTRUÇÃO DO ESTADO DO CONHECIMENTO SOBRE INICIAÇÃO CIENTÍFICA NA EDUCAÇÃO BÁSICA
}

\author{
Victor Hugo Nedel OLIVEIRA ${ }^{\mathrm{i}}$ \\ Daniel Giordani VASQUES ${ }^{\text {ii }}$
}

\begin{abstract}
RESUMO
A iniciação científica na escola básica trata-se de importante estratégia de aprendizagem. O principal objetivo da investigação foi construir o estado do conhecimento das pesquisas sobre IC na escola e a pergunta que guiou o estudo foi: o que as produções científicas vêm dizendo sobre as relações entre a iniciação científica na educação básica? Foi realizada pesquisa no banco de dados do IBICT, com recorte temporal de 2010 e 2020. Foram selecionados dez trabalhos, a maior parte dos quais da região Sul. As palavras-chave "IC" e "ensino médio" destacaram-se. Sobre as estratégias metodológicas, a maioria foi de entrevistas. Todos os trabalhos apresentaram potencialidades da IC para os estudantes e é possível considerar que o conhecimento sobre as práticas de IC fomenta tal estratégia como potencial pedagógico.
\end{abstract}

PALAVRAS-CHAVE: Iniciação Científica; Escola; Ensino Médio; Ensino Fundamental; Ciência.

\section{THE CONSTRUCTION OF THE STATE OF KNOWLEDGE OF SCIENTIFIC INITIATION AT BASIC EDUCATION}

\begin{abstract}
Scientific initiation (SI) in elementary school is an important learning strategy. The main objective of the investigation was to build the state of knowledge of research on SI at school and the question that guided the study was: what have scientific productions been saying about the relationship between scientific initiation in basic education? Research was carried out in the IBICT database, with a time frame of 2010 and 2020. Ten works were selected, of which, most of them in the southern region. The keywords "SI" and "high school" stood out. Regarding methodological strategies, most were interviews. All works presented the potential of SI for students. It is possible to consider that knowledge about SI practices fosters such a strategy as a pedagogical potential.
\end{abstract}

KEYWORDS: Scientific initiation; School; High school; Elementary School; Science.

\footnotetext{
${ }^{\mathrm{i}}$ Doutor em Educação pela Pontifícia Universidade Católica do Rio Grande do Sul (PUC-RS). Professor do Departamento de Humanidades da Universidade Federal do Rio Grande do Sul (UFRGS). E-mail: victor.juventudes@gmail.com - ORCID iD: https://orcid.org/0000-0001-5624-8476.

ii Doutor em Ciências do Movimento Humano pela Federal do Rio Grande do Sul (UFRGS). Professor do Departamento de Expressão e Movimento da Universidade Federal do Rio Grande do Sul (UFRGS). E-mail: dgvasques@hotmail.com - ORCID iD: https://orcid.org/0000-0001-8955-9676.
} 


\section{LA CONSTRUCCIÓN DEL ESTADO DEL CONOCIMIENTO SOBRE LA INICIACIÓN CIENTÍFICA EN LA EDUCACIÓN BÁSICA}

\section{RESUMEN}

La iniciación científica en la escuela básica es una estrategia de aprendizaje importante. El objetivo principal de la investigación fue construir el estado del conocimiento de la investigación sobre IC en la escuela y la pregunta que guió el estudio fue: ¿qué han estado diciendo las producciones científicas sobre la relación entre la iniciación científica en la educación básica? La investigación se llevó a cabo en la base de datos IBICT, con un calendario de 2010 y 2020. Se seleccionaron 10 trabajos, de los cuales, la mayoría de ellos en la región sur. Las palabras clave "IC" y "escuela secundaria" se destacaron. En cuanto a las estrategias metodológicas, la mayoría fueron entrevistas. Todos los trabajos presentaron el potencial de IC para los estudiantes. Es posible considerar que el conocimiento sobre las prácticas de IC fomenta una estrategia como un potencial pedagógico.

PALABRAS CLAVE: Iniciación Científica; Escuela; Enseñanza secundaria. Enseñanza primaria; Ciencias.

\section{INTRODUÇÃO}

A utilização da Iniciação Científica (IC) no âmbito da escola básica vem sendo ampliada por diversas razões, entre elas, a compreensão de que a inserção da IC se configura um desafio com foco na inovação curricular. O método científico e seu emprego no ambiente escolar produzem muitos ganhos aos estudantes, professores, aprendizado e comunidade, se desenvolvido a partir de estratégias pedagógicas adequadas. Estudar a ciência por um viés social colabora na reflexão sobre as práticas científicas realizadas: o que se alcança como resultados de investigações não está dissociado dos interesses e motivações para suas realizações (LATOUR, 2000). Há que se entender, portanto, das intencionalidades dos usos da ciência e da iniciação científica, no âmbito da escola básica.

É inestimável o valor da pesquisa científica no meio escolar como forma de aprendizado científico e instrumento para aprofundar os conhecimentos construídos em sala de aula. Silveira (2015) traz à baila a discussão acerca da formação científica no ensino médio, a partir de estudo desenvolvido sobre o Programa Institucional de Bolsas de Iniciação Científica para o Ensino Médio (Pibic-EM) do Conselho Nacional de Desenvolvimento Científico e Tecnológico ( $\mathrm{CNPq}$ ), em um caso no Estado do Rio de Janeiro. Silveira e Cassiani (2016), por sua vez, discutem a iniciação científica no ensino fundamental, a partir de atores como a escola e algumas problematizações entre ciência, tecnologia e sociedade. 
Oliveira (20219 também apresenta experiência de orientação científica nos anos finais do ensino fundamental, relatando e problematizando o cotidiano docente ao desenvolver pesquisas científicas com seus estudantes. Logo, o debate a respeito do uso da iniciação científica na escola extrapola a discussão sobre qual nível de ensino seria mais apropriado, visto que o método científico tem a capacidade de adaptar-se às mais diferentes realidades, mediante transposição didática de seus docentes.

O processo de construção do estado do conhecimento, por seu turno, configura-se importante etapa de todo o processo de pesquisa científica. Tal constituição própria já foi apontada por Morosini e Fernandes (2014) como a associação dos processos de identificação, registro, categorização que busquem produzir reflexão e síntese sobre a produção científica de determinada área, em certo espaço de tempo, a partir de periódicos, teses, dissertações e livros sobre uma temática específica.

Esse trabalho artesanal, de uma investigação que busque identificar, registrar e categorizar pesquisas já realizadas acerca de determinada área ou campo do conhecimento, adquire relevância, pois, em conjunção com as leituras de Biancha et al. (2004), é possível perceber que elas pontuam que a tarefa de catalogação de informações decorrentes da produção atualizada a respeito do tema de pesquisa constitui-se de etapa de visualização e ponderação mais densa sobre o estado de coisas, as quais se relacionam com a área de pesquisa e o tema da pesquisa: iniciação científica na escola básica. Nesse sentido, é importante avaliar as continuidades teóricas e metodológicas, o quanto se redunda, se avança ou se se silencia na produção dos saberes científicos, evitando, assim, a cristalização do conhecimento e provocando o movimento de busca sempre pelo "novo" na ciência.

Para o entendimento do corpus da pesquisa, reporta-se a Moraes e Galiazzi (2011), que afirmam não somente que o corpus trata do conjunto de informações sistematizadas na forma de texto, mas também que a definição e a delimitação do corpus são funções do pesquisador, o qual deve-se manter atento durante todo esse processo.

A partir do que já fora exposto, utilizou-se da seguinte pergunta de pesquisa: "O que as produções científicas vêm dizendo sobre as relações entre a iniciação científica na educação básica?”. O objetivo geral da pesquisa foi, dessa forma, construir o estado do conhecimento das pesquisas sobre iniciação científica na educação básica, a partir de dados

Revista e-Curriculum, São Paulo, v. 19, n.3, p. 1240-1262, jul./set. 2021 
coletados no banco de dados do Instituto Brasileiro de Informação em Ciência e Tecnologia (IBICT). As justificativas que guiaram a realização da investigação, portanto, configuram-se a produção de novos conhecimentos a partir de pesquisas desenvolvidas no âmbito do processo de iniciação científica na escola básica. Igualmente, apregoa-se a necessidade de proporcionar a criação de conhecimentos que gerem uma melhor interação professor-alunos com relação ao tema da ciência, amplamente presente na sociedade e, por vezes, tão controversa ${ }^{1}$. De todas as formas, muitos benefícios podem ser encontrados a partir de um levantamento de informações sobre determinado objeto de investigações, a partir de uma temática recortada em particular.

\section{METODOLOGIA}

Foi realizada pesquisa no banco de dados do IBICT, a partir das teses e dissertações defendidas e publicadas referentes ao estado do conhecimento de pesquisa sobre o tema "Iniciação Científica na Educação Básica".

O IBICT tem sua origem em 1954, dada a necessidade apontada pela Organização das Nações Unidas para a Educação, a Ciência e a Cultura (UNESCO) para que o Brasil tivesse um centro nacional de bibliografia e documentação. $\mathrm{Na}$ atualidade, o instituto conta com diversificados canais para a pesquisa, sistema de divulgação de dados científicos e um dos principais bancos de dados do País, congregando trabalhos acadêmicos de distintos níveis e diferentes áreas do conhecimento. A coleta de dados nesse repositório é significativa para a pesquisa não somente por representar um importante canal de divulgação científica no País, mas também pelo fato de reunir variados tipos de trabalhos científicos, como já fora explicitado.

A investigação foi realizada para localizar trabalhos acadêmicos relacionados ao tema de pesquisa e em uma etapa de análise dos dados. O recorte temporal constituiu-se no intervalo dos anos de 2010 até 2020, por conveniência, no intuito de verificar as produções mais atuais e já publicadas dentro do campo de estudos. Os descritores eleitos para as etapas de pesquisa foram: "Pesquisa"; "Iniciação Científica"; "Escola"; "Educação Básica"; “Iniciação Científica Júnior”. Foi realizado, a partir daí, um estudo qualitativo, de caráter exploratório, cujo objetivo foi identificar, por meio da leitura dos resumos dos trabalhos 
encontrados, quais seriam os selecionados para a construção do corpus da pesquisa, tendo como foco os trabalhos que mais se aproximaram do objeto de estudo ora apresentado.

Para a primeira etapa de análises, de caráter mais quantitativo, as categorias tipo de trabalho (tese ou dissertação), ano de publicação, instituição de publicação, região do país da instituição, tipo de fomento e palavras-chave foram compiladas e colocadas em referência, para que se pudesse estabelecer um quantitativo de análise inicial referente aos trabalhos encontrados e selecionados para composição do corpus da investigação. Além de elencar e quantificar, nessa etapa analítica foi possível considerar situações e problematizações acerca de tais categorias.

Para a segunda etapa de análises, de caráter mais qualitativo, foram elencados e destacados os objetivos gerais das investigações em análise, de maneira a verificar, diretamente, quais os objetivos e como a iniciação científica se fazia presente ou não nesses propósitos. Na sequência, foram observadas as principais estratégias de coleta de dados propostas nas metodologias dos trabalhos, de maneira a reconhecer quais as estratégias mais recorrentes nesse tipo de investigação e se, porventura, verificou-se algum tipo inovador no âmbito da metodologia. Por fim, nessa etapa, foram listadas e categorizadas as principais conclusões das investigações analisadas, de maneira a reconhecer as proximidades e os distanciamentos das percepções e análises sobre IC nas pesquisas analisadas.

Quanto à natureza, tratou-se de uma pesquisa aplicada (GIL, 2007), pois os conhecimentos produzidos a partir da investigação podem ser diretamente utilizados nos planejamentos e nas aulas, como poderão ser adotados por outros professores ou pesquisadores que tiverem acesso aos dados do estudo, nas mais diversas realidades. Quanto à abordagem, configurou-se como uma pesquisa quantitativo-qualitativa, porquanto buscou trabalhar com dados numéricos e dados qualitativos, a partir da categorização e classificação das informações coletadas dos trabalhos que compuseram o corpus analítico da investigação.

Quanto aos seus objetivos, tratou-se de uma pesquisa exploratória, pois objetivou proporcionar maior familiaridade com um problema, a partir de levantamento bibliográfico, além da análise dos exemplos verificados. Com relação aos procedimentos técnicos, a investigação enquadra-se como uma pesquisa bibliográfica, pois foi elaborada a partir de material já publicado: teses e dissertações. Essa categoria de pesquisa é um tipo de revisão

Revista e-Curriculum, São Paulo, v. 19, n.3, p. 1240-1262, jul./set. 2021 
bibliográfica e levantamento bibliográfico. Nesse mesmo sentido, Gil (2007, p. 44) aponta que as características desse tipo de pesquisa são formadas por investigações sobre a análise das diversas posições acerca de um problema, no caso, o da Iniciação Científica na Educação Básica.

Em observância e atendimento às questões éticas na pesquisa, em virtude de tratar-se de investigação realizada exclusivamente com textos científicos para revisão da literatura científica, ela é dispensada de avaliação pelo sistema CEP/CONEP, de acordo com as normativas éticas vigentes.

\section{RESULTADOS}

Ao aplicar os recortes selecionados ao processo de busca no banco de dados do IBICT, foram identificados 19 trabalhos no nível de teses e dissertações. Após a etapa da leitura flutuante dos resumos destes trabalhos, foram selecionados dez trabalhos por possuírem aderência mais relevante ao que se buscou com a investigação. O Quadro 1 apresenta a listagem, em ordem alfabética de sobrenome dos autores, dos trabalhos encontrados e escolhidos para análise.

Quadro 1 - Teses e dissertações selecionadas para análise

\begin{tabular}{|l|l|l|}
\hline \multicolumn{1}{|c|}{ Autor } & \multicolumn{1}{|c|}{ Título } & \multicolumn{1}{|c|}{ Nível } \\
\hline $\begin{array}{l}\text { CORREA, André } \\
\text { Luís da Costa }\end{array}$ & $\begin{array}{l}\text { Rolando dados, criando histórias, aprendendo história } \\
\text { o uso do RPG como instrumento de iniciação científica } \\
\text { no ensino de história }\end{array}$ & $\begin{array}{l}\text { Mestrado Profissional } \\
\text { em Ensino de História }\end{array}$ \\
\hline $\begin{array}{l}\text { COUTO, Mary Rose } \\
\text { de Assis Moraes }\end{array}$ & $\begin{array}{l}\text { Os Clubes de Ciências e a Iniciação à Ciência: uma } \\
\text { Proposta de Organização no Ensino Médio }\end{array}$ & $\begin{array}{l}\text { Mestrado Profissional } \\
\text { em Ensino de } \\
\text { Ciências }\end{array}$ \\
\hline DAMINELLI, Elisa & $\begin{array}{l}\text { A pesquisa e a produção de conhecimento nos } \\
\text { Institutos Federais de Educação, Ciência e Tecnologia } \\
\text { no RS: um estudo sobre a iniciação científica com } \\
\text { estudantes do ensino médio técnico }\end{array}$ & $\begin{array}{l}\text { Doutorado } \\
\text { Educação }\end{array}$ \\
\hline $\begin{array}{l}\text { GONÇALVES, } \\
\text { Daniela Antunes da } \\
\text { Costa }\end{array}$ & $\begin{array}{l}\text { A iniciação científica no ensino médio: contexto atual, } \\
\text { desafios e perspectivas na área de ciências da natureza }\end{array}$ & $\begin{array}{l}\text { Mestrado } \\
\text { Educação } \\
\text { Ciências }\end{array}$ \\
\hline
\end{tabular}




\begin{tabular}{|c|c|c|}
\hline $\begin{array}{l}\text { LIMA, Sônia Maria } \\
\text { Pereira de }\end{array}$ & $\begin{array}{l}\text { Inovação pedagógica, práticas pedagógicas inovadoras } \\
\text { e concepções docentes no macrocampo iniciação } \\
\text { científica e pesquisa do PROEMI }\end{array}$ & $\begin{array}{l}\text { Mestrado } \\
\text { Educação }\end{array}$ \\
\hline $\begin{array}{l}\text { OLIVEIRA, Adriano } \\
\text { de }\end{array}$ & $\begin{array}{l}\text { A iniciação científica júnior (ICJ): aproximações da } \\
\text { educação superior com a educação básica }\end{array}$ & $\begin{array}{l}\text { Doutorado } \\
\text { Educação }\end{array}$ \\
\hline $\begin{array}{l}\text { OLIVEIRA, Fátima } \\
\text { Peres Zago de }\end{array}$ & $\begin{array}{l}\text { Pactos e impactos da iniciação científica na formação } \\
\text { dos estudantes do ensino médio }\end{array}$ & $\begin{array}{lr}\text { Doutorado r } & \text { em } \\
\text { Educação } & \text { Científica } \\
\text { Tecnológica } & \end{array}$ \\
\hline $\begin{array}{l}\text { OLIVEIRA, Gisele } \\
\text { Brandão Machado de }\end{array}$ & $\begin{array}{l}\text { Percursos dos jovens de escolas públicas de ensino } \\
\text { médio e Profissional no Programa de iniciação } \\
\text { científica júnior da UFMG }\end{array}$ & $\begin{array}{l}\text { Doutorado } \\
\text { Educação, em } \\
\text { Conhecimento } \\
\text { Inclusão Social }\end{array}$ \\
\hline $\begin{array}{l}\text { PRIMAVERA, } \\
\text { Andressa Pereira }\end{array}$ & $\begin{array}{l}\text { Iniciação científica no ensino médio: contribuições do } \\
\text { Programa Ciência na Escola }\end{array}$ & $\begin{array}{l}\text { Mestrado em Ensino } \\
\text { de Ciências e } \\
\text { Matemática }\end{array}$ \\
\hline $\begin{array}{l}\text { ROSA, Marlusa } \\
\text { Benedetti da }\end{array}$ & $\begin{array}{l}\text { A inclusão da instituição escola na cultura digital e a } \\
\text { construção de novos paradigmas a partir da iniciação } \\
\text { científica na educação básica }\end{array}$ & $\begin{array}{l}\text { Doutorado } \\
\text { Informática } \\
\text { Educação }\end{array}$ \\
\hline
\end{tabular}

Fonte: Organização dos autores (2020).

O Quadro 1 apresenta a área de pós-graduação stricto sensu desenvolvida em cada um dos trabalhos selecionados, bem como a titulação obtida pelos autores das produções acadêmicas. É possível verificar, portanto, que é múltipla a realidade de origem das investigações sobre IC na Educação Básica, a partir de estudos em campos da educação e do ensino, bem como suas variantes. Além disso, identificam-se pesquisa em nível de mestrado profissional e acadêmico, além daquelas em nível de doutorado.

A partir da realidade apresentada no Quadro 1, referente aos trabalhos selecionados para comporem o corpus analítico da investigação, é possível constatar que, com relação ao tipo de trabalho, houve distribuição equitativa entre teses e dissertações. O fato de $50 \%$ das produções selecionadas para análise serem dissertações de mestrado (20\% profissional e 30\% acadêmico) e os outros 50\% serem teses de doutorado representa a diversidade analítica que se produz, no sentido de encontrar trabalhos com diferentes escopos e níveis de profundidade analítica, na medida em que existem textos selecionados mirando a IC na escola por variadas 
áreas do conhecimento, em diferentes Programas de Pós-Graduação (PPGs) e em distintos níveis de estudos.

No que diz respeito ao ano de publicação dos trabalhos selecionados para análise, foi construído o Gráfico 1, apresentando os quatro anos nos quais houve ocorrência de publicação dos materiais, quais sejam: 2013, 2014, 2017 e 2018.

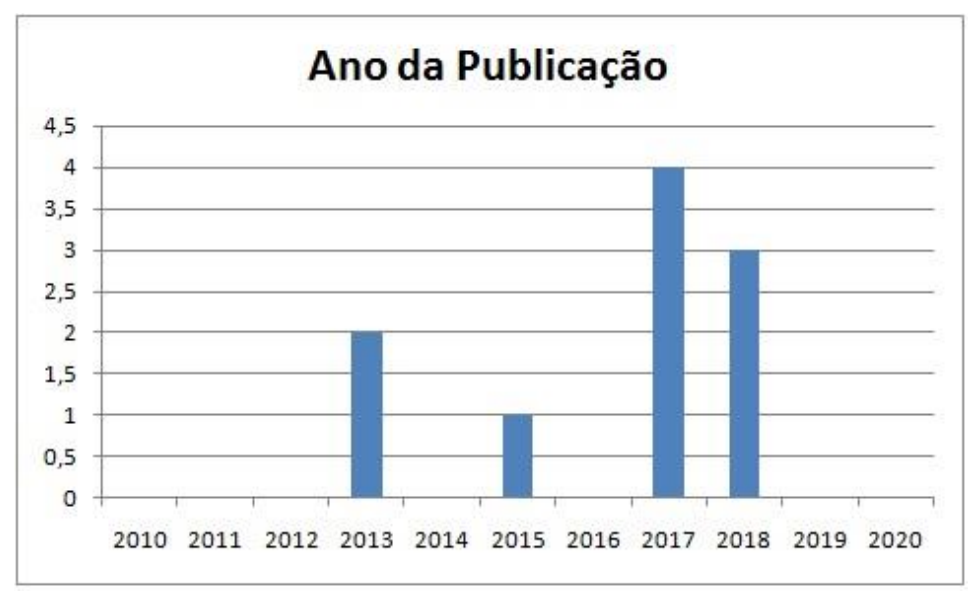

Gráfico 1 - Ano de publicação dos trabalhos Fonte: Organização dos autores (2020).

Levando em consideração que o recorte temporal adotado para a investigação compreendeu o intervalo entre os anos de 2010 e 2020, ou seja, dez anos de levantamento, visto que o ano de 2020 ainda está inconcluso, foram encontrados trabalhos em apenas quatro anos. Destes, os anos mais próximos ao final do recorte temporal escolhido despontaram com maior número: 2017, com quatro pesquisas e 2018 com três investigações. Como se tratou de um espaço de tempo relativamente extenso, é possível inferir que as produções sobre o tema de IC na educação básica têm se concentrado em períodos mais recentes, principalmente pelo fato de que a introdução da Iniciação Científica como recurso didático-metodológico no âmbito da escola configura-se em processo contemporâneo, com poucos anos de ampla inserção, para além de experiências pontuais.

Ao elencar as instituições dos PPGs dos trabalhos que compuseram o corpus da presente investigação, foi possível constatar que duas delas foram a origem de $50 \%$ dos trabalhos e outras cinco ficaram, individualmente, com um trabalho cada, conforme Gráfico 2 observado na sequência. 


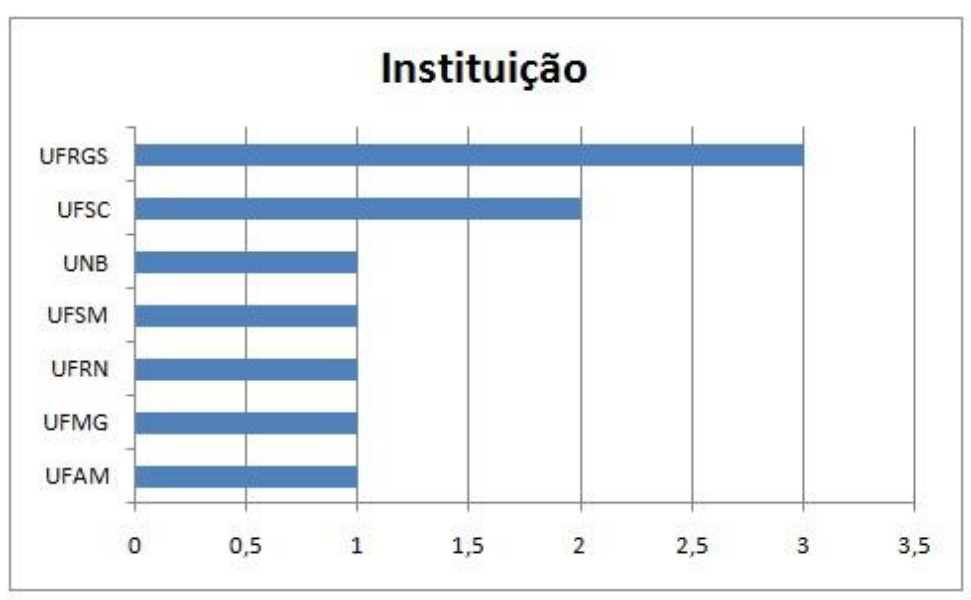

Gráfico 2 - Instituição de publicação. Fonte: Organização dos autores (2020).

Verifica-se, a partir da leitura do Gráfico 2, que a Universidade Federal do Rio Grande do Sul (UFRGS) foi a instituição de origem de três trabalhos (30\%) e a Universidade Federal de Santa Catarina (UFSC), de dois trabalhos (20\%); as demais - UNB, UFSM, UFRN, UFMG e UFAM -, de um trabalho (10\%) cada. É imperativo assinalar, a partir da observação do Gráfico 2, igualmente, que as sete instituições que acolheram a realização de investigações sobre a temática da Iniciação Científica no âmbito da educação básica são de ensino superior públicas e do sistema federal. Tal constatação ganha relevância analítica em tempos nos quais a educação e a ciência estão em constante defesa, em meio aos ataques institucionais e sociais que vêm sofrendo, nos mais diferentes campos, em especial, no político. Torna-se importante perceber, portanto, que os núcleos de investigação sobre ciência e iniciação à ciência na escola básica são frutos dos esforços das universidades públicas federais, institutos que não se cansam de fomentar o pensamento crítico, embasado em fatos e que promovam a reflexão e o estado de bem-estar da sociedade.

A partir dos dados coletados e apresentados relativos às instituições de origem dos trabalhos que compuseram o corpus analítico da pesquisa, foi possível identificar e catalogar a densidade de regiões do Brasil conforme a regionalização proposta pelo Instituto Brasileiro de Geografia e Estatística (IBGE), das instituições de origem dos PPGs onde foram produzidas as investigações. É expressiva a concentração de produções na região Sul do País, que contabiliza seis trabalhos do corpus analítico (60\%), a partir das pesquisas oriundas das seguintes universidades: UFRGS, UFSC e UFSM. As demais regiões do Brasil, Sudeste, 
Nordeste, Norte e Centro-Oeste ficaram representadas com apenas uma investigação em cada (10\%). Aqui, encontra-se outro nó analítico importante: a concentração de investigações em uma única região e um apagamento das produções sobre o tema da Iniciação Científica no âmbito da escola básica nas demais partes do País. Diversos motivos poderiam explicar tal panorama encontrado, a partir do tema da investigação, dos descritores encaminhados, do recorte temporal adotado e do banco de dados utilizado, o que causou, por si só, uma ocorrência única de cenário possível a ser descoberto. O fato é que se materializou uma realidade regional desigual e tal discrepância merece atenção.

Levando em conta a amostragem de PPGs que deram origem às investigações do corpus da presente pesquisa, foi efetuado levantamento de conceitos dos referidos programas, a partir da última avaliação da Coordenação de Aperfeiçoamento de Pessoal de Nível Superior (CAPES) disponível, ${ }^{2}$ realizada no ano de 2017. Nenhum dos programas obteve conceito 1 ou 2, o que significaria seu fechamento, entre outras consequências. O quadro que se apresentou pode ser verificado no Gráfico 3.

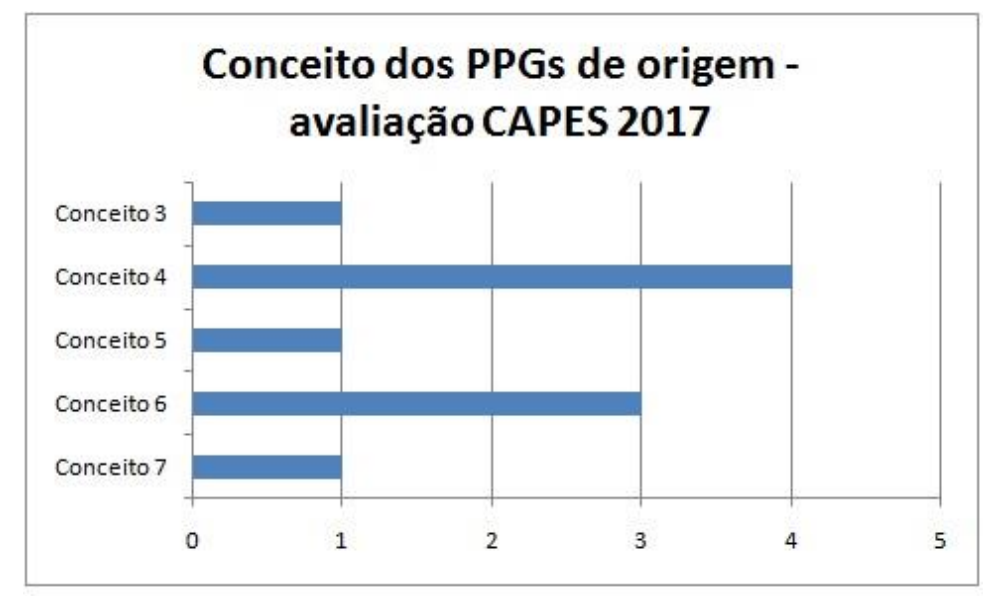

Gráfico 3 - Conceitos dos PPGs de origem dos trabalhos. Fonte: Organização dos autores (2020).

O Gráfico 3 demonstra a concentração em quatro PPGs (40\%) aos quais lhes foram atribuídos conceito CAPES 4, equivalente à avaliação de "bom". Com relação ao conceito CAPES 3, "regular", foi atribuído a apenas um PPG (10\%). Sobre o conceito CAPES 5, "muito bom", foi conferido a um PPG (10\%), igualmente. Na esfera dos PPGs de nível de "excelência", a partir dos conceitos CAPES 6 e 7, foram verificados três PPGs no nível 6 (30\%) e um PPG no nível máximo, 7 (10\%). Ao cruzar os dados dos PPGs com investigações 
em nível de doutorado, e em cruzamento com o fato de que somente Programas com esse nível podem alçar conceitos 6 ou 7, verificou-se que 40\% dos programas foram aferidos com tal nota, o que deixou um deles (10\%) com conceito menor do que 6. Ainda, a maioria dos programas com apenas mestrado, ou, ainda, que não eram acadêmicos, e sim profissionalizantes, ficaram abaixo na nota máxima que poderiam alcançar: conceito 5 .

Ainda a respeito do tema da qualidade na Pós-Graduação, sabe-se que o financiamento dessa etapa de ensino trata-se de elementar constituinte na qualidade dos programas e das relações ali desenvolvidas, uma vez que os pós-graduandos poderiam, ao menos em tese, ter dedicação exclusiva às investigações, realizar experiências no exterior, compra de materiais e recursos, entre outros aspectos. A maioria das pesquisas não contou com financiamento público direto para as investigações, o que se percebe pelo quantitativo de $70 \%$ de trabalhos sem aporte financeiro ao pesquisador. Dos 30\% dos trabalhos que receberam bolsas de pesquisa, dois deles (20\%) tiveram bolsa da CAPES e um deles (10\%) da Fundação de Amparo à Pesquisa do Estado do Amazonas (FAPEAM). Tal cenário é preocupante, na medida em que existe pouco financiamento para investigações do campo das ciências humanas, quadro cada vez mais assustador, especialmente a partir das recentes políticas de desmonte da pesquisa brasileira, sobretudo o afastamento da área de humanidades e artes, por exemplo, da concorrência em editais e bolsas de pesquisa. É urgente que os gestores públicos dirijam esforços para aumentar o investimento em pesquisas no campo da educação e das humanidades, como é o caso das investigações sobre Iniciação Científica na escola, um tema essencial e que diz respeito, seguramente, à qualidade da educação e da ciência do País.

Em uma análise das palavras-chave empregadas nas investigações estudadas, que poderiam variar com relação aos descritores da investigação em algumas expressões, foi possível, a partir da compilação delas e consequente trabalho de registro e análise, construir a nuvem de palavras que é apresentada na sequência, de maneira que se identificaram as palavras ou expressões em maior ocorrência (maior tamanho das letras) ou em menor ocorrência (menor tamanho das letras).

Revista e-Curriculum, São Paulo, v. 19, n.3, p. 1240-1262, jul./set. 2021 


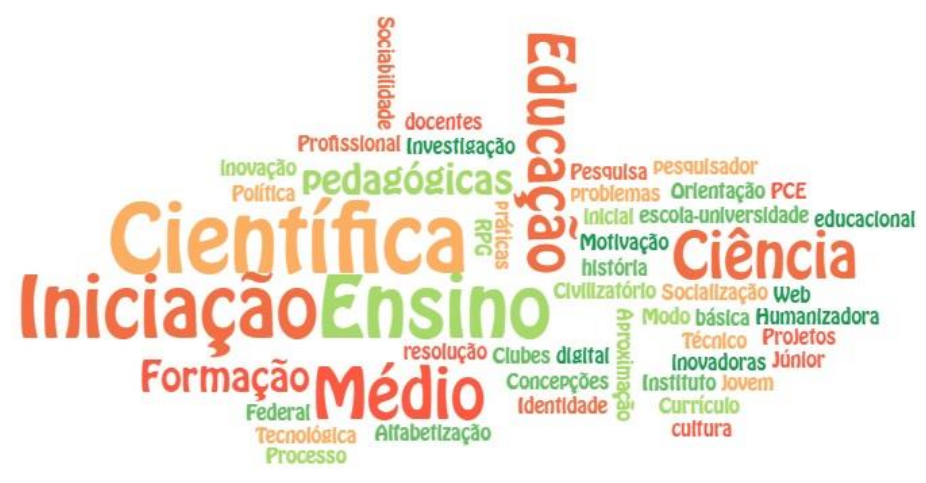

Figura 1 -Nuvem de palavras das palavras-chave utilizadas pelos trabalhos Fonte: Organização dos autores (2020).

É possível visualizar que a expressão mais recorrente nas palavras-chave das investigações foi "Iniciação Científica", por estar em expressiva evidência na nuvem de palavras elaborada. Tal expressão também compôs o mapa de descritores elencados para o rastreio das investigações que vieram a formar o corpus analítico do trabalho, o que não causa grande surpresa, no sentido de que as pesquisas justamente tratavam do assunto de Iniciação Científica, portanto seria esperado que ocorresse tal expressão. Na sequência, percebe-se a expressão "ensino médio" em destaque na nuvem de palavra, embora ela não constasse nos descritores previstos para coleta dos trabalhos, verificou-se que a maioria das investigações participantes da análise tratava da IC na etapa do ensino médio (70\%) e o restante (30\%), no ensino fundamental. Essa informação abre margem para provocar reflexão no sentido de os interesses investigativos sobre IC na escola básica voltarem-se para a etapa final da escolarização, e não para os primeiros anos ou até mesmo os anos finais do ensino fundamental. Existe, a partir da análise, portanto, um importante espaço a ser ocupado pelos pesquisadores que despendem esforços para pensar sobre IC na escola: o ensino fundamental. Por fim, das palavras que mais emergiram, a dupla "ciência" e "educação" ganhou destaque na imagem com as palavras-chave das investigações. Muitas possibilidades de reflexões poderiam ser construídas a partir da intersecção entre os conceitos de ciência e educação, mas o que prevalece, acredita-se, é o caráter de indissociabilidade entre os dois campos: não se faz educação sem bases científicas e não se faz ciência sem um processo educacional na retaguarda. Ciência e Educação são, portanto, complementares e inseparáveis. 
Avançando no campo de análises das investigações selecionadas, procurou-se verificar seus objetivos, de maneira a reconhecer o que se buscou, de modo particular, o que se queria alcançar em cada um dos trabalhos examinados. O Quadro 2 apresenta o "objetivo geral" das dez pesquisas que compuseram o corpus de análise da presente investigação, por ordem dos sobrenomes dos autores.

Quadro 2 - Objetivos das investigações

\begin{tabular}{|c|c|}
\hline Autor, data & Objetivo Geral da Investigação \\
\hline CORRÊA, 2017 & $\begin{array}{l}\text { Refletir sobre as possibilidades do RPG como uma prática de produção de } \\
\text { narrativas que estimule a iniciação científica no espaço escolar a partir de } \\
\text { experiências realizadas nos anos finais do ensino fundamental da EMEF Paulo VI. }\end{array}$ \\
\hline COUTO, 2017 & $\begin{array}{l}\text { Investigar os Clubes de Ciências como estratégia de Iniciação à Ciência na } \\
\text { Educação Básica, sobretudo no Ensino Médio. }\end{array}$ \\
\hline $\begin{array}{l}\text { DAMINELLI, } \\
2018\end{array}$ & $\begin{array}{l}\text { Investigar e compreender de que forma a participação em projetos de pesquisa, } \\
\text { através da Iniciação Científica tem contribuído para a formação dos estudantes de } \\
\text { Ensino Médio Técnico e para a consolidação da pesquisa e produção de } \\
\text { conhecimentos nos três Institutos Federais de Educação, Ciência e Tecnologia } \\
\text { localizados no Rio Grande do Sul. }\end{array}$ \\
\hline $\begin{array}{l}\text { GONÇALVES, } \\
2018\end{array}$ & $\begin{array}{l}\text { Analisar o desenvolvimento da Iniciação Científica, na área de Ciências da } \\
\text { Natureza, no Ensino Médio da Rede Estadual de Ensino da cidade de Alegrete. }\end{array}$ \\
\hline LIMA, 2017 & $\begin{array}{l}\text { Estudar as concepções dos professores de Ciências da Natureza e Matemática sobre } \\
\text { inovação pedagógica e as práticas pedagógicas inovadoras no Macrocampo de } \\
\text { Iniciação Científica e Pesquisa do ProEMI. }\end{array}$ \\
\hline $\begin{array}{l}\text { OLIVEIRA, } \\
2015\end{array}$ & $\begin{array}{l}\text { Investigar a política de formação inicial de pesquisadores na Educação Básica (EB) } \\
\text { por meio da Iniciação Científica Júnior (ICJ), com foco no Programa Institucional } \\
\text { de Bolsas de Iniciação Científica para o Ensino Médio (PIBIC-EM). }\end{array}$ \\
\hline $\begin{array}{l}\text { OLIVEIRA, } \\
2017\end{array}$ & $\begin{array}{l}\text { Identificar as contribuições da Iniciação Científica no Ensino Médio para a } \\
\text { formação dos estudantes do IFC - Rio do Sul. }\end{array}$ \\
\hline $\begin{array}{l}\text { OLIVEIRA, } \\
2013\end{array}$ & $\begin{array}{l}\text { Analisar os percursos de socialização e sociabilidade de estudantes de ensino } \\
\text { médio e profissional que participaram do Provoc na UFMG no período de } 2007 \text { a } \\
2009 \text {. }\end{array}$ \\
\hline $\begin{array}{l}\text { PRIMAVERA, } \\
2018\end{array}$ & $\begin{array}{l}\text { Investigar as contribuições de Projetos em Ciências Biológicas aprovados no PCE } \\
\text { em 2017, para Educação Científica de estudantes do Ensino Médio de escolas } \\
\text { estaduais públicas. }\end{array}$ \\
\hline ROSA, 2013 & $\begin{array}{l}\text { Acompanhar o processo de implementação de uma proposta curricular que integra } \\
\text { projetos de iniciação científica desenvolvidos por alunos da Educação Básica e o } \\
\text { uso das tecnologias digitais na modalidade "um computador para um aluno". }\end{array}$ \\
\hline
\end{tabular}

Fonte: Organização dos autores (2020).

É possível perceber no Quadro 2, a partir da exposição, análise e comparação dos objetivos gerais de tais investigações, que os objetos de análise sobre IC na escola básica dos trabalhos são diversos, abarcando estudos específicos desde projetos institucionais sobre IC, 
análise de documentos orientadores sobre IC, estratégias didático-metodológicas sobre aplicação de IC e reflexões teóricas acerca do tema. Os objetivos das investigações representam, de maneira geral, aquilo que se quer atingir com a pesquisa, seja em nível de mestrado (acadêmico ou profissional) ou doutorado. Por mais que, em uma avaliação preliminar, sejam poucos trabalhos de pós-graduação que se dedicam à investigação da IC na educação básica, é notória a percepção de que eles buscam, a seu modo, contribuir com o campo de estudos e colaboram na produção do conhecimento.

É a partir do Quadro 2, sobre os objetivos gerais dos estudos, que se podem extrair os verbos de comando dos referidos objetivos, ou seja, o verbo no modo infinitivo que dá início ao objetivo geral, o qual diz muito sobre o que se deseja alcançar com a investigação, na medida em que comanda uma ação a ser desenvolvida ou realizada. Nesse sentido, utilizamos os dez verbos de comando dos objetivos gerais dos trabalhos para construção do Quadro 3, a partir da classificação proposta por Bloom (1950), na qual são distribuídos os verbos a partir da intencionalidade a que eles se destinam, de algo mais simples ao mais complexo, seja por uma ação de conhecimento, compreensão, aplicação, análise, síntese ou, por fim, avaliação.

Quadro 3 - Classificações dos Objetivos

\begin{tabular}{|c|c|c|c|}
\hline Classificação & Número de trabalhos & Fontes & Verbos \\
\hline \multirow{2}{*}{ Conhecimento } & 1 & LIMA, 2017 & Estudar \\
\hline Compreensão & 1 & ROSA, 2013 & Acompanhar \\
\hline Aplicação & 1 & OLIVEIRA, 2017 & Identificar \\
\hline Análise & 1 & CORRÊA, 2017 & Refletir \\
\hline Síntese & 2 & $\begin{array}{c}\text { COUTO, 2017 } \\
\text { DAMINELLI, 2018 } \\
\text { OLIVEIRA, 2015 } \\
\text { PRIMAVERA, 2018 }\end{array}$ & Investigar \\
\cline { 2 - 4 } & 2 & $\begin{array}{c}\text { GONÇALVES, 2018 } \\
\text { OLIVEIRA, 2013 }\end{array}$ & Analisar \\
\hline Avaliação & - & - & - \\
\hline
\end{tabular}

Fonte: Organização dos autores (2020).

Constata-se, a partir da leitura do Quadro 3, que a maioria dos verbos de comando dos objetivos gerais das investigações encontra-se na classificação de "análise", a partir de quatro trabalhos utilizando o verbo "investigar" (40\%) e dois, o verbo "analisar" (20\%). Na sequência, a classificação de "conhecimento" contou com duas pesquisas, que empregaram os 
verbos "estudar" (10\%) e "acompanhar" (10\%). As classificações de compreensão e aplicação tiveram um verbo de comando cada, sendo "identificar" (10\%) e "refletir" (10\%), respectivamente. As classificações de síntese e avaliação não apresentaram nenhum objetivo que contivesse verbo de comando a elas relacionado. Nesse sentido, é possível considerar que a maior parte das investigações sobre IC na educação básica (60\%) trata-se de pesquisas que buscam, a seu modo, analisar o cenário, o contexto, as condições e as estratégias concernentes à iniciação científica no contexto escolar. Embora não haja investigações em níveis mais complexos, a partir da categorização de Bloom (1950), o propósito de análise é de grande consideração a quem se dedica à pesquisa sobre o campo de conhecimento dos estudos da ciência, ainda mais quando o cenário no qual se estuda a ciência e sua iniciação corresponde ao das bases da educação.

Para atingir os objetivos propostos para as investigações estudadas, diversas estratégias metodológicas foram adotadas, na forma de estudos descritivos, exploratórios, de caso, entre outros. Assim, como estratégias de coleta dos dados das pesquisas, a partir de levantamento nos capítulos referentes às metodologias de trabalho investigativo, foi possível construir o Gráfico 4, com as principais estratégias de coleta de dados. Ressalta-se que uma investigação pode ter usado uma ou mais estratégia de coleta de dados, pelo que as porcentagens do gráfico ultrapassam os $100 \%$.

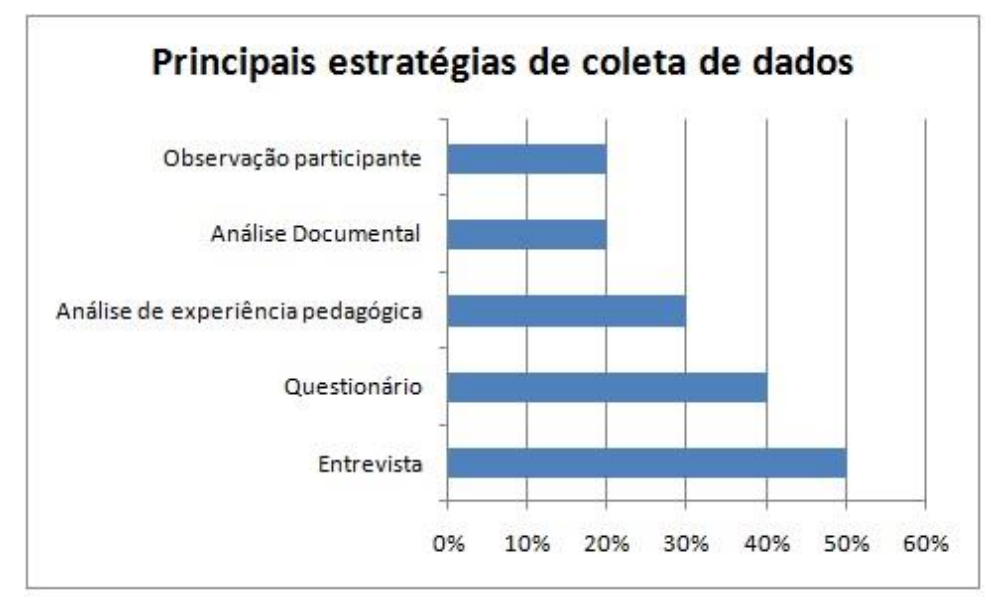

Gráfico 4 - Principais estratégias de coleta de dados utilizadas nas pesquisas.

Fonte: Organização dos autores (2020).

Revista e-Curriculum, São Paulo, v. 19, n.3, p. 1240-1262, jul./set. 2021 
A estratégia de coleta de dados mais usada pelos trabalhos que compuseram o corpus de análise da presente investigação foi a "entrevista", adotada em $50 \%$ das pesquisas. Os autores Goode e Hatt (1969, p. 237) já definiram entrevista como uma estratégia que "consiste no desenvolvimento de precisão, focalização, fidedignidade e validade de certo ato social como a conversação". Nesse sentido, a escuta aos atores envolvidos no processo de Iniciação Científica na escola básica tem se configurado técnica de coleta de dados mais utilizada, na medida em que possibilita coletar e, posteriormente, analisar os discursos produzidos por esses atores. Dando sequência, o questionário emerge como estratégia de coleta de dados em $40 \%$ dos trabalhos examinados, o que demonstra que há, com a necessidade de escuta proporcionada pela entrevista, a intenção de realizar mapeamento, caracterização e um entendimento de modo mais quantitativo com relação aos personagens e aos processos envolvidos na iniciação científica na escola. Em 30\% dos trabalhos, efetuou-se análise de alguma experiência didático-pedagógica. Nessas pesquisas, foi aplicada ou observada alguma utilização da IC em situações didáticas específicas e, a partir dessa experiência, foi desenvolvida a investigação. Em $20 \%$ dos trabalhos, foi feita análise documental, a partir da coleta e exame de documentos oficiais de instituições de ensino básico e superior, relacionados ao contexto de IC. Em outros $20 \%$, foi efetuada observação participante, a partir das experiências dos próprios investigadores, em suas realidades docentes, com a inserção da IC no âmbito da escola básica. É a amálgama das estratégias de coleta de dados, nas diversas investigações, cada uma com seus objetivos e suas características, que promove o entendimento de que não há uma única forma de coletar dados, para posterior análise, sobre a produção de conhecimentos relacionados à IC na educação: na medida em que são múltiplas as realidades, também devem sê-lo as formas de olhá-las e procurar entendê-las.

O entendimento de que os objetivos das pesquisas transpostos em estratégias de coleta e análise de dados levam às considerações dos trabalhos estudados propiciou que fossem levantados e categorizados os principais achados das investigações sobre IC na escola básica, os quais estão representados na Figura 2, a partir de seis categorias criadas de maneira que pudessem ser compreendidos o quão amplas também são as possibilidades de respostas às perguntas formuladas nas diversas pesquisas. 


\begin{tabular}{|c|c|c|c|c|c|c|c|c|c|c|}
\hline \multirow[b]{2}{*}{ Categorias de conclusões } & \multicolumn{10}{|c|}{ Autores selecionados } \\
\hline & $\begin{array}{l}\text { CORRÊA, } \\
2017\end{array}$ & $\begin{array}{l}\text { COUTO, } \\
2017\end{array}$ & $\begin{array}{l}\text { DAMINELLI, } \\
2018\end{array}$ & $\begin{array}{c}\text { GONÇALVES, } \\
2018\end{array}$ & $\begin{array}{l}\text { LIMA, } \\
2017\end{array}$ & $\begin{array}{l}\text { OLIVEIRA, } \\
2015\end{array}$ & $\begin{array}{l}\text { OLIVEIRA, } \\
2017\end{array}$ & $\begin{array}{l}\text { OLIVEIRA, } \\
2013\end{array}$ & $\begin{array}{l}\text { PRIMAVERA, } \\
2018\end{array}$ & $\begin{array}{c}\text { ROSA, } \\
2013\end{array}$ \\
\hline $\begin{array}{l}\text { Contribuiçốes da IC na } \\
\text { formação dos estudantes da } \\
\text { EB }\end{array}$ & $\mathrm{x}$ & $\mathrm{x}$ & $\mathrm{x}$ & $\mathrm{x}$ & $\mathrm{x}$ & $\mathrm{x}$ & $\mathrm{x}$ & $\mathrm{x}$ & $\mathrm{x}$ & $\mathrm{x}$ \\
\hline $\begin{array}{l}\text { Motivação dos estudantes } \\
\text { com a IC }\end{array}$ & & $\mathrm{x}$ & & & & $\mathrm{x}$ & $\mathrm{x}$ & $\mathrm{x}$ & $\mathrm{x}$ & $\mathrm{x}$ \\
\hline $\begin{array}{l}\text { Autonomia dos projetos dos } \\
\text { estudantes }\end{array}$ & & $\mathrm{x}$ & & $\mathrm{x}$ & & $\mathrm{x}$ & $\mathrm{x}$ & $\mathrm{x}$ & & $\mathrm{x}$ \\
\hline $\begin{array}{l}\text { Relação sala de aula/outras } \\
\text { disciplinas e IC }\end{array}$ & $\mathrm{x}$ & & & & & $\mathrm{x}$ & $\mathrm{x}$ & & $\mathrm{x}$ & $\mathrm{x}$ \\
\hline $\begin{array}{l}\text { Mediaçôes/orientações dos } \\
\text { professores na IC }\end{array}$ & & & & & & $\mathrm{x}$ & $\mathrm{x}$ & $\mathrm{x}$ & $\mathrm{x}$ & $\mathrm{x}$ \\
\hline $\begin{array}{l}\text { Limitações epistemológicas } \\
\text { dos professores da EB sobre } \\
\text { IC }\end{array}$ & & & & & $\mathrm{x}$ & & $\mathrm{x}$ & & & \\
\hline
\end{tabular}

Figura 2 - Quadro com categorias construídas a partir das conclusões. Fonte: Organização dos autores (2020).

Em uma primeira leitura, é imperativo destacar que todos os trabalhos analisados apresentaram significativas potencialidades das contribuições da IC na formação dos estudantes da educação básica, como observado na primeira categoria do quadro de conclusões apresentado na Figura 2. Daminelli (2018, p. 230), por exemplo, é enfática, ao afirmar que "a Iniciação Científica traz contribuições relevantes para a formação dos estudantes de nível médio". Oliveira (2015, p. 254), por sua vez, afirma que "os jovens bolsistas e suas famílias percebem o PIBIC-EM como uma porta de entrada no campo acadêmico, potenciando o ingresso e a permanência na universidade e o acesso ao saber mais qualificado", ou seja, para além da prática e da vivência com IC no Ensino Médio, a possibilidade de que esses estudantes ainda sejam bolsistas, na modalidade júnior, potencializa ainda mais tais condicionantes.

Ainda, foi possível perceber que a iniciação científica na escola básica possui especial fator de motivação aos estudantes que a descobrem e que nela exercem seu papel de produtores de conhecimento. Para isso, Couto (2017, p. 107) revelou que "esses estudantes foram motivados pela curiosidade e possibilidade de ingressarem em um mundo onde a investigação oportuniza vivências, movimentando e construindo conhecimento". Por sua vez, Oliveira (2013, p. 208) brinda-nos com a reflexão sobre como a participação desses estudantes em eventos científicos motiva-os a seguir na busca pelo conhecimento: "ao dizerem da participação em eventos acadêmicos nas mostras científicas, por exemplo, os estudantes demonstram se sentir competentes para aplicar socialmente os conhecimentos 
adquiridos sob novas formas". Fica evidente, portanto, o quão significativos são os sentidos atribuídos à IC na escola por parte dos estudantes.

Há, entre as categorias das conclusões dos trabalhos analisados, um importante alerta para os processos de operacionalização da IC na educação básica: as limitações epistemológicas de alguns professores, como é apontado por Lima (2017, p. 247), quando afirma que: "o professor para planejar práticas pedagógicas inovadoras nesse macrocampo, precisa pensar cientificamente, ser crítico e criativo, bem como dispor de domínio de conhecimentos sobre a educação científica". Também como apontado por Oliveira (2017, p. 271): “orientar IC para estudantes do EM [Ensino Médio] requer formação pedagógica e epistemológica no que se refere às relações entre os sujeitos, às orientações como processo e às interferências da ciência no processo civilizatório". É importante considerar, portanto, sabedores das deficiências encontradas nos processos de formação inicial e continuada dos professores, que a orientação de Iniciação Científica na escola básica exige, antes de tudo, que os professores orientadores tenham envolvimento com a ciência, seja mediante a realização de pesquisas de pós-graduação, seja pelo constante contato com textos e materiais científicos, seja por meio da atualização pedagógica pela formação continuada, entre outros.

Outros tópicos analíticos puderam, igualmente, ser considerados a partir da leitura das considerações finais dos trabalhos analisados, como a autonomia dos projetos dos estudantes, que pode ser dada pela mediação das escolhas de temáticas de investigação e estratégias metodológicas, por exemplo, com seus orientadores, ou seja, trata-se de uma autonomia tutorada por quem, de alguma maneira, já teve mais contato ou experiência com o processo científico.

Ao mesmo tempo, outra categoria abordou as mediações e orientações dos professores na IC no âmbito da escola básica: distintos aspectos podem ser identificados nessa relação: acadêmicos, cognitivos ou emocionais, pois há um entendimento de que, em razão do nível de ensino, os professores orientadores de IC na escola básica ajam como tutores dos jovens pesquisadores para além de suas investigações, de maneira a atuarem como supervisores e aconselhadores das demais esferas dos processos escolares em andamento.

Foi evidenciada, por fim, a relação dos processos de sala de aula, a partir das demais disciplinas dos currículos escolares com a Iniciação Científica: é urgente e necessário maior 
envolvimento entre o que se constrói e produz nas diversas disciplinas e o que se pesquisa na escola básica, de maneira que tal diálogo encontre maior fluidez.

\section{CONCLUSÃO}

Neste trabalho, tratou-se da Iniciação Científica no âmbito da educação básica, refletindo a respeito dos estudos mais recentes, em nível de pós-graduação, sobre o assunto em tela. O principal objetivo da investigação foi construir o estado do conhecimento das pesquisas sobre iniciação científica na educação básica, a partir de dados coletados no banco de dados do IBICT. Para atingir esse propósito, realizou-se busca no banco de dados do IBICT, a partir das teses e dissertações defendidas e publicadas referentes ao estado do conhecimento de pesquisa acerca do tema "Iniciação Científica na Educação Básica", com recorte temporal entre anos de 2010 e 2020 e com os seguintes descritores: "Pesquisa"; "Iniciação Científica"; "Escola"; "Educação Básica"; "Iniciação Científica Júnior”.

Foram encontrados 19 trabalhos de pós-graduação, a partir dos recortes de descritores e de tempo definidos, dos quais, após leitura dos resumos, dez foram selecionados para análise, compondo o corpus da investigação: cinco dissertações e 5 teses. Do recorte temporal de dez anos escolhido (2010 - 2020), apenas identificaram-se trabalhos em quatro anos 2013, 2015, 2017 e 2018 -, sendo o ano de 2017 o que apresentou maior número de investigações relacionadas ao tema.

Ao reconhecer as instituições de origem dos trabalhos, a UFRGS deu acolhida à produção de três daqueles e a UFSC, a duas pesquisas. As demais instituições foram origem de um trabalho cada. Associado ao tópico das instituições dos trabalhos, pôde-se constatar que a região sul do Brasil foi a que obteve maior número de trabalhos produzidos (60\%), sendo as demais regiões do País proveniência de um trabalho cada. Ao expandir a análise dos espaços de investigação e entrando no campo das avaliações da CAPES com relação aos PPGs dos trabalhos analisados, à maioria desses PPGs foi atribuído o conceito 4, tendo, também, PPGs em todos os outros conceitos, de 3 até 7. A extensa maioria das investigações não contou com financiamento externo para realização dos estudos e, das que contaram, duas foram com bolsas CAPES e uma com bolsa da FAPEAM.

Revista e-Curriculum, São Paulo, v. 19, n.3, p. 1240-1262, jul./set. 2021 
Quando se analisaram as palavras-chave dos trabalhos, foi possível perceber que as expressões mais recorrentes foram "Iniciação Científica", o mesmo nome do objeto de estudo específico da investigação, e "Ensino Médio", etapa da escolarização básica mais recorrente como campo investigativo das pesquisas. Ao examinar os objetivos gerais das dez investigações selecionadas para a pesquisa, percebeu-se a diversidade do campo de estudo da Iniciação Científica na escola básica, a partir dos diferentes recortes adotados para pesquisa nos trabalhos analisados. Ainda, no tocante aos objetivos, em análise comparativa à proposição de Bloom (1950), sobre uma taxonomia dos verbos de comando, foi possível verificar que a maioria dos trabalhos encontrou-se no nível da competência de "análise".

Sobre as estratégias metodológicas das pesquisas, a maior parte delas contou com entrevistas, como recurso de coleta de dados, seguidos de outras estratégias, como questionário, análise de experiência pedagógica, análise documental e observação participante. Assim, foi possível constatar, igualmente, que as pesquisas não se utilizaram apenas de uma estratégia, mas de múltiplas, e, em todos os casos, associadas à revisão bibliográfica.

Quanto às considerações ou aos "achados dos trabalhos", todos estes apresentaram potencialidades das contribuições da IC na formação dos estudantes da educação básica, assim como foi possível verificar que a IC possui especial fator que produz motivação nos estudantes que a conhecem e praticam. As limitações epistemológicas dos professores também foram alvo de destaque nas considerações de alguns trabalhos, o que acende o alerta para a constante necessidade de formação e prática continuada em ciência, daqueles que possam vir a ser orientadores de trabalhos de IC na escola.

Fazer ciência, no mundo contemporâneo, é um desafio em vários campos: econômicos, sociais, culturais e epistêmicos, por exemplo, mas fazê-lo no Brasil contemporâneo representa um desafio maior, que engloba todos os já citados: as questões políticas. Produzir ciência na escola brasileira, portanto, configura-se um processo que oportuniza o crescimento dos estudantes, seus professores e suas comunidades em vários campos, cognitivo, social, cultural, porém, mais do que isso, trata-se de um forte processo de resistência, perante as ondas negacionistas que, lamentavelmente, assolam o Brasil contemporâneo. 
Conhecer o campo de pesquisa sobre Iniciação Científica na escola básica pode ser um passo importante para a compreensão dos desafios que tal prática vem encontrando nos últimos anos, mas, também, possibilita aos pesquisadores identificar as potencialidades que tais trabalhos produzem e proporcionam, a fim de tentar entender as limitações e as fortalezas que as práticas de IC na escola vivem e, assim, buscar trilhar caminhos nos quais a ciência seja importante eixo condutor da vida cotidiana.

Há o entendimento de que a construção do estado do conhecimento não é a simples repetição do que outros pesquisadores já inferiram em seus trabalhos. Trata-se de um exercício controlado de pesquisa, busca, seleção, curadoria e reflexão sobre o que já fora escrito sobre determinado tema, nesse caso, sobre Iniciação Científica na Escola Básica. Não é possível, nem pela constituição do estado da arte, nem por outra forma qualquer, saber dos processos, das situações e vivências subjetivas pelas quais cada pesquisador passou durante seu trabalho, e, quanto a isso, há grande respeito e admiração.

\section{REFERÊNCIAS}

BIANCHA, Carla et al. O estado da arte da pesquisa sobre o fracasso escolar (1991-2002): um estudo introdutório. Educação e Pesquisa, São Paulo, n. 1, p. 51-72, jan./abr. 2004. Disponível em: https://www.scielo.br/scielo.php?pid=S151797022004000100004\&script=sci_arttext\&tlng=pt. Acesso em: 28 jul. 2020

BLOOM, Benjamin et al. (ed.). Taxonomy of educational objectives: The classifications educational goals. Handbook 1. Cognitive Domain. New York: McKay, 1950.

CORREAA, André Luís da Costa. Rolando dados, criando histórias, aprendendo história: o uso do RPG como instrumento de iniciação científica no ensino de história. 2017. Dissertação (Mestrado Profissional em Ensino de História) - Programa de Pós-Graduação em Ensino de História, Universidade Federal do Rio Grande do Sul, Porto Alegre, 2017.

COUTO, Mary Rose de Assis Moraes. Os clubes de ciências e a iniciação à ciência: uma Proposta de Organização no Ensino Médio. 2017. Dissertação (Mestrado Profissional em Ensino de Ciências) - Universidade de Brasília, Brasília, 2017.

DAMINELLI, Elisa. A pesquisa e a produção de conhecimento nos Institutos Federais de Educação, Ciência e Tecnologia no RS: um estudo sobre a iniciação científica com estudantes do ensino médio técnico. 2018. Tese (Doutorado em Educação) - Universidade Federal do Rio Grande do Sul, Porto Alegre, 2018. 
GIL, Antônio Carlos. Métodos e técnicas de pesquisa social. São Paulo: Atlas, 2007.

GONÇALVES, Daniela Antunes da Costa. A iniciação científica no ensino médio: contexto atual, desafios e perspectivas na área de ciências da natureza. 2018. Dissertação (Mestrado em Educação nas Ciências) - Universidade Federal de Santa Maria, Santa Maria, 2018.

GOODE, William; HATT, Paul. Métodos em pesquisa social. 2. ed. São Paulo: Nacional, 1968.

LATOUR, Bruno. Ciência em ação: como seguir cientistas e engenheiros sociedade afora. São Paulo: Unesp, 2000.

LIMA, Sônia Maria Pereira de. Inovação pedagógica, práticas pedagógicas inovadoras e concepções docentes no macrocampo iniciação científica e pesquisa do PROEMI. 2017. Dissertação (Mestrado em Educação) - Universidade Federal do Rio Grande do Norte, Natal, 2017.

MORAES, Roque; GALIAZZI, Maria do Carmo. Análise textual discursiva. 2. ed. Ijuí: UNIJUÍ, 2011.

MOROSINI, Marília Costa; FERNANDES, Cleoni Maria Barboza. Estado do Conhecimento, finalidades e interlocuções. Educação por Escrito, Porto Alegre, v. 5, n.2, p. 154-164, 2014. Disponível em:

https://revistaseletronicas.pucrs.br/ojs/index.php/porescrito/article/view/18875/12399 . Acesso em: 28 jul. 2020.

OLIVEIRA, Adriano de. A iniciação científica júnior (ICJ): aproximações da educação superior com a educação básica. 2015. Tese (Doutorado em Educação) - Universidade Federal de Santa Catariana, Florianópolis, 2015.

OLIVEIRA, Fátima Peres Zago de. Pactos e impactos da iniciação científica na formação dos estudantes do ensino médio. 2017. Tese (Doutorado em Educação Científica Tecnológica) - Universidade Federal de Santa Catariana, Florianópolis, 2017.

OLIVEIRA, Gisele Brandão Machado de. Percursos dos jovens de escolas públicas de ensino médio e Profissional no Programa de iniciação científica júnior da UFMG. 2013. Tese (Doutorado em Educação, Conhecimento e Inclusão Social) - Universidade Federal de Minas Gerais, Belo Horizonte, 2013.

OLIVEIRA, Victor Hugo Nedel. Pesquisa científica escolar no Ensino Fundamental: relatos de uma experiência. Cadernos do Aplicação. Porto Alegre. v. 32. n. 1. p. 95-104, jan./jul. 2019. Disponível em: https://seer.ufrgs.br/CadernosdoAplicacao/article/view/88852/56394 Acesso em: 08 abr. 2020.

PRIMAVERA, Andressa Pereira. Iniciação científica no ensino médio: contribuições do Programa Ciência na Escola. 2018. Dissertação (Mestrado em Ensino de Ciências e Matemática) - Universidade Federal do Amazonas, Manaus, 2018. 
ROSA, Marlusa Benedetti da. A inclusão da instituição escola na cultura digital e a construção de novos paradigmas a partir da iniciação científica na educação básica. 2013. Tese (Doutorado em Informática na Educação) - Universidade Federal do Rio Grande do Sul, Porto Alegre, 2013.

SILVEIRA, Zuleide. Formação científica no nível médio de ensino: primeiras aproximações. Boletim Técnico do Senac, Rio de Janeiro, v. 41, n. 1, p. 36-57, jan./abr. 2015. Disponível em: https://www.bts.senac.br/bts/article/view/55/42. Acesso em: 28 jul. 2020.

SILVEIRA, José Carlos da; CASSIANI, Suzani. Iniciação científica no ensino fundamental: a escola e seu lugar problematizador das relações entre ciência, tecnologia e sociedade. Sensose, Porto, v. III, n. 2, 2016. Disponível em: http://sensos-e.ese.ipp.pt/?p=11715. Acesso em: 28 jul. 2020.

\section{NOTAS:}

1 Para Latour (2000), a noção de controvérsia pretende descrever a existência (no caso específico, a não existência) de argumentos contrários com relevância suficiente para questionar as ações que estão postas. A sua visualização permite a abertura das caixas-pretas da ciência, mostrando as associações e os interesses dos atores.

${ }^{2}$ Disponível em: http://avaliacaoquadrienal.capes.gov.br/resultado-da-avaliacao-quadrienal-2017-2. Acesso em: 18 maio 2020.

Recebido em: 20/05/2020

Aprovado em: 14/08/2020 